SANTOS, G.R.; CAFÉ FILHO, A.C. Reação de genótipos de melancia ao crestamento gomoso do caule. Horticultura Brasileira, Brasília, v.23, n.4, p.945950, out-dez 2005.

\title{
Reação de genótipos de melancia ao crestamento gomoso do caule ${ }^{1}$
}

\author{
Gil Rodrigues dos Santos²; Adalberto C. Café Filho ${ }^{3}$ \\ ${ }^{2}$ Universidade Federal de Tocantins, Campus de Gurupi, C. Postal 66, 77400-000 Gurupi-TO; ${ }^{3}$ Universidade de Brasília, Depto. \\ Fitopatologia, 70910-900 Brasília-DF; gilrsan@uol.com.br
}

\section{RESUMO}

Face à importância do crestamento gomoso do caule e à escassez de relatos da reação de genótipos de melancia na literatura nacional e internacional, este trabalho teve por objetivo avaliar a resposta de genótipos comerciais de melancia ao crestamento gomoso. No campo, estudou-se o nível de infecção nas folhas em delineamento de blocos ao acaso com nove cultivares de melancia e quatro repetições, com inoculação de duas plantas por parcela aos 43 dias após o plantio (DAP). Foram avaliadas as cultivares Crimson Sweet, Onix, Rubi, Safira, Eureka, Georgia, Sheila, Savana e Riviera. Em casa de vegetação, estudou-se a infecção no caule em vasos, com delineamento inteiramente casualizado, com três repetições, em esquema fatorial de $9 \times 3$, sendo o fator "a" = cultivares e o fator "b" = isolados. Foram avaliadas as mesmas cultivares do ensaio de campo, com inoculação artificial com disco de micélio aos 15 dias após a semeadura, quando do surgimento da primeira folha definitiva. Os isolados de $D$. bryoniae utilizados na inoculação das plântulas foram: UnB 76 (Melão-DF), UnB 75 (Melancia-PE) e UnB 81 (Abóbora-DF). Dentre as cultivares avaliadas no campo, Riviera mostrou-se mais resistente e apresentou menores $(\mathrm{P} \leq 0,05)$ índices de infecção foliar aos 74 e 79 dias após plantio (DAP), e também menor valor da área abaixo da curva de progresso de doença (AACPD). Foram altamente suscetíveis Crimson Sweet, Rubi, Onix e Safira, que apresentaram os mais altos níveis de infecção nas folhas aos 74 DAP e também altos valores de AACPD. Na avaliação da doença no caule, em casa de vegetação, Riviera também apresentou a menor AACPD $(\mathrm{P} \leq 0,05)$. Foi significativa a correlação $(r=0,77)$ entre a resposta das cultivares em campo (resistência das folhas) e em casa de vegetação (resistência no caule).

Palavras-chave: Citrullus lanatus, Didymella bryoniae.

\begin{abstract}
Response of watermelon cultivars to gummy stem blight

Gummy stem blight, caused by Didymella bryoniae, is one of the most important watermelon diseases. Nevertheless, there are relatively few published studies on the response of watermelon genotypes to the disease. This paper reports results of studies on the response of commercially available watermelon cultivars to gummy stem blight. Leaf infection was studied in a randomized complete block field experiment with nine watermelon genotypes and four replicates. Two plants per experimental plot were inoculated 43 days after planting. Cultivars Crimson Sweet, Onix, Rubi, Safira, Eureka, Georgia, Sheila, Savana and Riviera were evaluated. Stem infection was studied in the greenhouse, in a completely randomized design, with three replicates, in a $9 \times 3$ factorial, where plant cultivars corresponded to factor "a" and pathogen isolates corresponded to factor " $b$ ". The same nine cultivars were examined following artificial inoculation with mycelial disks inserted into stems, 15 days after planting date, when plants were at the first adult leaf stage. The $D$. bryoniae isolates were UnB 76 (Melon-DF), UnB 75 (Watermelon$\mathrm{PE}$ ) and UnB 81 (Pumpkin-DF). In the field experiment, Riviera was the most resistant genotype, with significantly $(\mathrm{P} \leq 0.05)$ lower values of leaf infection at 74 and 79 DAP and the smallest area under disease progress curve (AUDPC). Crimson Sweet, Rubi, Onix and Safira were the most susceptible genotypes based on foliar disease levels 74 days after planting and also based on the AUDPCs. In the greenhouse, Riviera also presented the smallest $(\mathrm{P} \leq 0.05)$ AUDPC in stems. A significant correlation $(\mathrm{r}=0.77)$ was detected between disease measurements in the greenhouse (stem response) and in the field (foliar response).
\end{abstract}

Keywords: Citrullus lanatus, Didymella bryoniae.

(Recebido para publicação em 2 de dezembro de 2004 e aceito em 14 de setembro de 2005)

$\mathrm{D}$ entre as doenças da melancia (Citrullus lanatus) o crestamento gomoso do caule, ou cancro da haste, é uma das principais devido aos seus efeitos na redução da produtividade e qualidade dos frutos (SANTOS et al., 2005b). Os sintomas incluem cancro no caule, queima das folhas e também apodrecimento de frutos (SCHENCK, 1968). A doença vem despertando preocupação nos perímetros irrigados da região nordeste do Brasil (DIAS et al. 1996), e em outros países, como nos Estados Unidos (EVERTS, 1999; KEINATH; DUTHIE,
1998; SITTERLY; KEINATH, 1996; SCHENCK, 1960) e no Caribe (BALA; HOSEIN, 1986). O agente causal é o fungo Didymella bryoniae (Auersw) Rehm (=Mycosphaerella citrullina (C.O. Sm.) Gross.), anamorfo Ascochyta cucumis Fautrey \& Roum (=Phoma cucurbitacearum (Fr.) Sacc.), que tem como hospedeiras diversas espécies de Citrullus, Cucumis, Cucurbita, e outros gêneros da família Cucurbitaceae (KEINATH, 1995). Figueiredo e Cardoso (1964) registraram a doença pela primeira vez no Brasil, com o patógeno em sua forma assexuada. Recentemente, Café-Filho e Santos (2004) registraram e descreveram a forma perfeita de Didymella bryoniae no Brasil.

Em área de cultivo comercial, o controle químico aumentou a produção em até $16,9 \mathrm{t}$ por ha (SANTOS et al., 2005a). Em um estudo específico para estimativa de perdas de produção, verificou-se redução de até $19,2 \%$ na produtividade devido ao crestamento gomoso (SANTOS et al., 2005b). Entretanto, o controle químico do crestamento gomoso é dificultado devi-

${ }^{1}$ Parte da tese de doutorado do primeiro autor apresentada à Universidade de Brasília, UnB, Brasília, DF. 
do à rápida infecção das folhas pelo patógeno (ARNY; ROWE, 1991; VAN STEEKELENBURG, 1985), necessitando várias aplicações de fungicidas. Além disso, existem relatos de resistência do patógeno a determinados princípios ativos (EVERTS, 1999; MALATHRAKIS; VAKALOUNAKIS, 1983; SANTOS et al., 2004).

Até o momento, ainda há escassez de informação sobre a reação de genótipos de cucurbitáceas, com boa aceitação comercial, resistentes à doença, e diversos trabalhos relatam a busca de fontes de resistência para o melhoramento (DIAS et al., 1996; DUSI et al., 1994; MCGRATH et al., 1993; SUMNER; HALL, 1993; WEHNER; AMAND, 1993). Uma outra abordagem é a avaliação da resposta dos genótipos comerciais disponíveis ao crestamento gomoso. O conhecimento da resposta das cultivares à infecção por $D$. bryoniae, é importante para capacitar os produtores quanto à tomada de decisões agronômicas, e pode ter impacto imediato no manejo da doença. O controle via resistência genética, mesmo parcial, pode ser usado em conjunto com outras medidas e reduzir o uso de agrotóxicos, reduzindo o custo de produção e contribuindo para a melhor conservação do ecossistema. Segundo Cohen et al. (1993), além da preocupação com a saúde pública, os produtores rurais são motivados a otimizar as práticas culturais utilizando menos defensivos químicos e optando pela utilização de cultivares resistentes a doenças.

Sowell e Pointer (1962) identificaram o genótipo PI 189225 como fonte de resistência ao crestamento gomoso. Norton e Cosper (1985) confirmaram a resistência de PI 189225 e comentaram que este genótipo, além do PI 271778, possibilitaram retrocruzamentos que resultaram no lançamento de cultivares de melancia resistentes ao crestamento e outras doenças. No Brasil, Dias et al. (1996) examinaram 70 acessos de melancia quanto à resistência a $D$. bryoniae, incluindo PI 189225, o qual apresentou reação variável (suscetível a resistente) em diferentes ensaios. A cultivar Crimson Sweet, uma das mais plantadas no Brasil, foi utilizada como padrão de susceptibilidade. Esses auto- res encontraram seis fontes de resistência para uso em futuros trabalhos de melhoramento, sendo PI 189255 uma delas.

Exceto pelo estudo de Dias et al. (1996), são poucos os trabalhos envolvendo a identificação de fontes de resistência a $D$. bryoniae em melancia no Brasil. Nenhum trabalho foi encontrado comparando genótipos comerciais. Este trabalho teve por objetivo quantificar a resposta de genótipos comerciais de melancia ao crestamento gomoso do caule. Essa informação poderá ser útil para o manejo integrado da doença.

\section{MATERIAL E MÉTODOS}

\section{Avaliação da resistência nas folhas}

O estudo foi realizado de 9/12/2003 a 8/03/2004, em condições de campo na Estação Biológica da Universidade de Brasília, em Brasília, DF. O experimento foi instalado em local não cultivado nos dois anos anteriores e sem histórico de plantio de cucurbitáceas. Após aração e gradagem, a área foi adubada com 800 $\mathrm{kg} /$ ha da fórmula N-P-K 4-14-8. A semeadura foi feita em covas, no espaçamento de $2 \times 2 \mathrm{~m}$, colocando-se 5 sementes/cova a $2 \mathrm{~cm}$ de profundidade. Cada parcela foi composta por quatro covas semeadas com a mesma cultivar. Decorridos 30 dias após o plantio (DAP) foi feito o desbaste, deixando-se duas plantas por cova e em seguida foi realizada adubação de cobertura com 200 kg/ha da fórmula N-P-K 20-00-20. Durante todo o ensaio foram feitas três capinas de forma manual aos 15; 30 e 40 DAP e foi conduzido o direcionamento das ramas para o interior da parcela, visando-se evitar a mistura de ramas entre cultivares diferentes. O suprimento de água para as plantas foi conforme a distribuição das chuvas no local do ensaio. Foram feitas aplicações do inseticida Metamidofós na dose de 0,24 kg/ha, aos 20, 30 e 45 DAP, visando-se diminuir o nível de infestação de pragas. Não foram utilizados fungicidas durante a condução do trabalho. Aos 43 DAP duas plantas de cada parcela foram inoculadas utilizando-se um pedaço de caule de $10 \mathrm{~cm}$ de comprimento/planta, naturalmente infectado e obtido em cultivo comercial afetado pelo crestamento gomoso do caule. Após ferimento do colo por fricção com o fragmento infectado, este foi depositado ao lado da planta inoculada. Devido às condições do clima favoráveis à doença (chuvas, temperatura amena e alta umidade do solo e do ar, Figura 3) não foi feita câmara úmida nas plantas inoculadas. Estas serviram de foco inicial de inóculo. Foi utilizado o delineamento em blocos ao acaso com nove tratamentos e quatro repetições. Os tratamentos constaram dos genótipos de melancia atualmente mais plantados no país: Crimson Sweet (cultivar) e dos híbridos Onix, Rubi, Safira, Eureka, Georgia, Sheila, Savana e Riviera.

Quando os primeiros sintomas da doença foram observados nas folhas, iniciou-se o monitoramento da doença, utilizando-se uma escala de notas de 0 a 9 onde: 0-planta sadia; 1 -menos de $1 \%$ da área foliar afetada; 3 -entre 1 e $5 \%$ da área foliar afetada; 5 -entre 6 e $25 \%$ da área foliar doente; 7-entre $26-50 \%$ da folha doente; 9-mais que $50 \%$ da área foliar afetada (SANTOS et al., 2005a). Para obtenção das curvas de progresso da doença, converteram-se as notas para porcentagens de área foliar doente pelo ponto médio de cada nota, em cada uma das parcelas estudadas aos 44; 49; 54; 59; 64; 69; 74; 79; 84 e 89 DAP. A cada avaliação, foram coletadas folhas infectadas visando-se comprovar a presença de $D$. bryoniae nas plantas, por meio de exame em microscópio estereoscópico e ótico. A Área Abaixo da Curva de Progresso de Doença (AACPD) de cada tratamento foi calculada segundo Shaner e Finney (1977) e a análise de variância e teste de média foram executados utilizando-se o programa SigmaStat v.2 (Jandel Scientific Software). Os materiais foram separados em classes de resistência com base nas AACPDs e nas porcentagens de área foliar atacadas em cada época de avaliação no campo, considerando-se Crimson Sweet como padrão de suscetibilidade (DIAS et al., 1996).

\section{Avaliação da resistência no caule}

Para o exame da resistência no caule foi conduzido um experimento em casa de vegetação, de maio a julho de 2004 , em vasos de polietileno, capaci- 
dade de $3,0 \mathrm{~kg}$, contendo uma mistura de terra vegetal + esterco, na proporção de 3:1. O substrato foi previamente desinfestado com brometo de metila e utilizado após 4 dias. Foram semeadas quatro sementes por vaso de cada cultivar e após a germinação das sementes e emergência das plântulas, foram mantidas duas plântulas em cada vaso. A unidade experimental foi constituída por três vasos com um total de seis plantas por cada repetição. A irrigação foi realizada diariamente com regador molhando-se toda a planta. O experimento foi repetido para confirmação dos resultados.

Utilizou-se o delineamento inteiramente casualizado com três repetições e em esquema fatorial de $9 \times 3$, sendo o fator " $a$ " = cultivares e o fator " $\mathrm{b}$ " = isolados. As mesmas cultivares estudadas em campo foram estudados neste ensaio. Foram utilizados os seguintes isolados de $D$. bryoniae para inoculação no caule: UnB 81 (Abóbora-DF), UnB 76 (Melão-DF) e UnB 75 (Melancia-PE). A inoculação foi feita em plântulas com 15 dias decorridos da semeadura, quando do surgimento da primeira folha definitiva. Utilizou-se disco de micélio que ficou preso ao caule por meio de um alfinete estéril. Plântulas tratadas apenas com alfinete estéril representaram a testemunha. Após a inoculação, as plântulas ficaram sob câmara úmida por $24 \mathrm{~h}$ e em sala de incubação com fotoperíodo de $12 \mathrm{~h}$ e temperatura de $23 \pm 4^{\circ} \mathrm{C}$. Decorridas $24 \mathrm{~h}$ da inoculação iniciou-se diariamente a avaliação da doença nas plântulas por um período de oito dias. Utilizou-se uma escala de notas adaptada para doença no caule, onde: $0=$ ausência de doença; $1=$ presença de lesão no caule e $2=$ presença de lesão no caule e tombamento e morte das plântulas. Para avaliação da resistência à infecção no caule, considerou-se o progresso da doença nas seis plântulas de cada repetição durante os oito dias consecutivos.

Para análise estatística foi calculada a AACPD. A análise de variância, teste de médias e correlação dos dados de AACPD de campo e casa de vegetação foram executadas utilizando-se o programa SigmaStat v.2 (Jandel Scientific Software).

Tabela 1. Avaliação da resistência nas folhas de cultivares de melancia, em duas épocas, ao crestamento gomoso em condições de campo. Brasília, UnB, 2004.

\begin{tabular}{lcc}
\hline \multirow{2}{*}{ Cultivar } & \multicolumn{2}{c}{ Area foliar infectada (\%) $^{*}$} \\
\cline { 2 - 3 } & 74 DAP $^{* *}$ & 79 DAP \\
\hline Crimson Sweet & $26,5 \mathrm{a}$ & $41,5 \mathrm{ab}$ \\
Onix & $26,5 \mathrm{a}$ & $35,8 \mathrm{ab}$ \\
Rubi & $26,5 \mathrm{a}$ & $47,3 \mathrm{a}$ \\
Safira & $26,5 \mathrm{a}$ & $41,5 \mathrm{ab}$ \\
Sheila & $17,8 \mathrm{ab}$ & $41,5 \mathrm{ab}$ \\
Georgia & $15,0 \mathrm{ab}$ & $47,3 \mathrm{a}$ \\
Eureka & $12,0 \mathrm{ab}$ & $32,3 \mathrm{ab}$ \\
Savana & $6,0 \mathrm{ab}$ & $20,8 \mathrm{ab}$ \\
Riviera & $3,0 \mathrm{~b}$ & $9,0 \mathrm{~b}$ \\
\hline
\end{tabular}

*Médias seguidas de mesma letra nas colunas não diferem entre si pelo Teste de Tukey a 5\% de probabilidade. Os dados originais foram transformados para $\sqrt{\mathrm{x}}$. **DAP: dias após plantio.

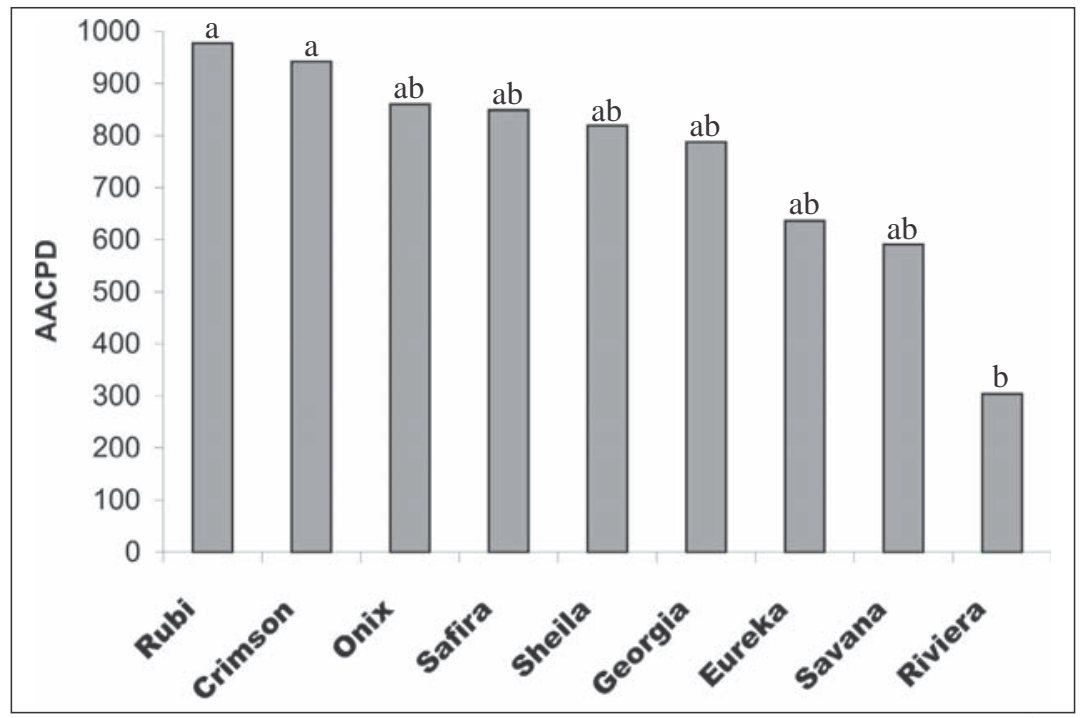

Figura 1. Reação de cultivares de melancia ao crestamento gomoso nas folhas, pela Área Abaixo da Curva de Progresso de Doença (AACPD), em condições de campo. Brasília, UnB, 2004. Médias seguidas de mesma letra não diferem entre si pelo Teste de Tukey a 5\% de probabilidade. Brasília, UnB, 2004.

\section{RESULTADOS E DISCUSSÃO}

No ensaio desenvolvido em campo, os sintomas foram detectados nas folhas aos seis dias após a inoculação do patógeno no caule em todos as cultivares. Esse fato demonstrou que ocorre rápida infecção do patógeno quando existem fontes de inóculo no plantio sob condições climáticas favoráveis (Figura 3). A cv. Riviera mostrou-se mais resistente à infecção de $D$. bryoniae nas folhas, diferindo estatisticamente de vários genótipos aos 74 e 79 DAP (Tabela 1) e apresentando menor valor de
AACPD quando comparado com Rubi e Crimson Sweet (Figura 1). As curvas de progresso da doença indicam visualmente as diferenças das dinâmicas de progresso em cada classe de resistência (Figura 2). Aos 74 DAP, foram mais suscetíveis Crimson Sweet, Rubi, Onix e Safira, as quais apresentaram os mais altos níveis de infecção nas folhas e (Tabela 1). Crimson Sweet e Rubi também apresentaram os mais altos valores de AACPD, diferindo significativamente de Riviera (Figura 1). As cvs. Sheila, Geórgia, Eureka e Savana, apresentaram resposta intermediária, pois não se separaram de Crimson Sweet ou de 


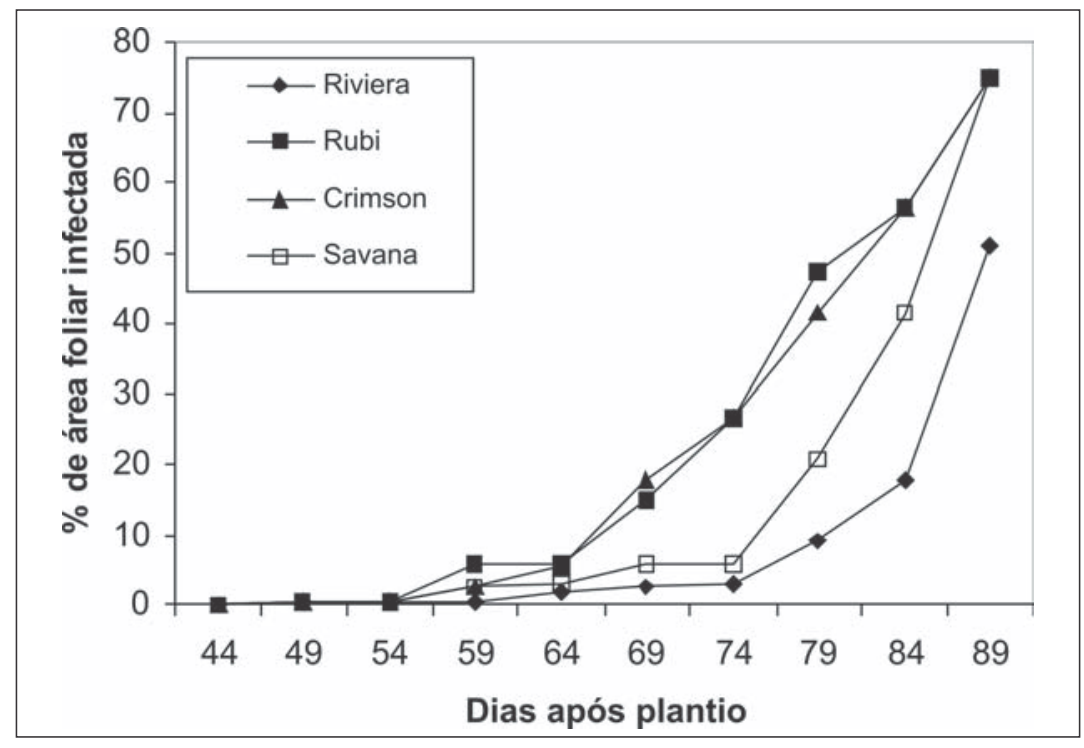

Figura 2. Curvas de progresso do crestamento gomoso do caule em cultivares de melancia representativas de diferentes níveis de resistência. 'Riviera' e 'Crimson Sweet' representam as cultivares mais resistente e suscetível respectivamente. Brasília, UnB, 2004.

Tabela 2. Áreas Abaixo da Curva de Progresso de Doença (AACPD) de cultivares de melancia inoculados no caule com isolados de $D$. bryoniae, em casa de vegetação. Brasília, UnB, 2004.

\begin{tabular}{lc}
\hline Genótipo & AACPD* $^{*}$ \\
\hline Georgia & $11,2 \mathrm{a}$ \\
Safira & $11,1 \mathrm{a}$ \\
Crimson Sweet & $10,9 \mathrm{a}$ \\
Onix & $10,4 \mathrm{a}$ \\
Sheila & $10,2 \mathrm{a}$ \\
Eureka & $9,5 \mathrm{ab}$ \\
Rubi & $9,4 \mathrm{ab}$ \\
Savana & $9,0 \mathrm{ab}$ \\
Riviera & $7,8 \mathrm{~b}$ \\
\hline
\end{tabular}

*Médias seguidas de mesma letra nas colunas não diferem entre si pelo Teste de Tukey a 5\% de probabilidade. Os dados originais foram transformados para $\sqrt{x}$. Os dados representam a média de 3 isolados.

Riviera, nem pela área foliar atacada aos 74 DAP, nem pela AACPD (Tabela 1, Figura 1). De um modo geral, até os 64 DAP, a maioria das cultivares apresentou um nível semelhante de infecção nas folhas. Esse período coincidiu com a formação e crescimento dos frutos. A partir dos 64 DAP houve aumento brusco na percentagem de área foliar infectada (Figura 2) nos genótipos mais suscetíveis (Rubi e Crimson Sweet) em relação àqueles intermediários ou resistentes (Riviera e Savana). As plantas deste grupo, principalmente Riviera, em condições de campo, mantiveram baixa percentagem de área foliar infectada até os 74 DAP, o qual coincide com o período da primeira colheita. Esta informação é importante para o produtor, pois pode exigir um menor número de aplicações de fungicidas até a primeira colheita, sem prejuízo à produção de frutos saudáveis a um custo mais baixo, quando comparado com genótipos mais suscetíveis.

O aumento da doença nesse estádio da cultura já foi observado anteriormente em 'Crimson Sweet' por Santos et al. (2005b), que registraram que a curva de progresso da doença nas folhas aumentou bruscamente, de forma exponencial, a partir de 75 DAP. Segundo os autores, o aumento progressivo da doença nesta fase relacionou-se com o início da colheita dos frutos, quando normalmente ocorrem injúrias nos ramos e nas folhas que são portas de entrada para o patógeno. De acordo com Svedelius e Unestan (1978), quando o tecido é mecanicamente afetado, ocorre exsudação de nutrientes importantes para o processo de infecção de $D$. bryoniae. Chiu e Walker (1949) verificaram que a germinação dos esporos de D. bryoniae foi estimulada pelos extratos das plantas. Van Steekelenburg (1985) anotou que o maior progresso da doença está associado com o maior desenvolvimento vegetativo da cultura devido à densa cobertura das folhas inferiores que reduz a evaporação e prolonga o período de molhamento foliar. Corroborando essa observação, Arny e Rowe (1991) constataram que a infecção em folhas e pecíolos de pepino por D. bryoniae foi mais influenciada pela duração do molhamento foliar do que pela temperatura. Além da influência desses fatores, também acredita-se que a movimentação de pessoas na colheita dentro da área plantada favorece a disseminação do patógeno e, assim, aumenta rapidamente a taxa de progresso da doença. A cv. Riviera manteve menores níveis de doença nas folhas quando comparada com outros genótipos até no último dia da avaliação, aos 89 DAP (Figura 2).

Mesmo com nível de resistência incompleto, vale salientar que 'Riviera' retardou o início da fase exponencial da doença (mas não o início do aparecimento dos sintomas) e a manteve em níveis baixos em épocas importantes como a fase de formação e crescimento de frutos. Contudo, após a primeira colheita dos frutos (74 DAP), o crestamento também aumentou consideravelmente nesta cultivar. Portanto, apesar desta cultivar ter mostrado maior nível de resistência que as demais, a resistência é parcial, e a doença pode alcançar índices elevados ao final do ciclo. Esse resultado concorda com outros autores que comentaram sobre a dificuldade no controle por resistência, e que nenhum genótipo de melancia comercializado atualmente tem alta resistência ao patógeno (PUNITHALINGAM; HOLLIDAY, 1972; BLANCARD et al., 1996; SITTERLY; KEINATH, 1996). 
Assim, o controle químico deve continuar como importante componente do manejo da doença em cultivares mais suscetíveis e bem aceitos comercialmente. Santos et al. (2005a), estudando o controle químico da doença em área de cultivo comercial, iniciaram as aplicações em Crimson Sweet aos 17 DAP e anotaram aumento da produção em até 16,9 t/ha. Os resultados deste trabalho indicam que o controle poderia ser iniciado mais tardiamente, especialmente nos genótipos mais resistentes (Figura 2), permitindo a redução do número de aplicações químicas.

Com relação às linhagens estudadas por outros autores, Sowell e Pointer (1962) identificaram o genótipo PI 189225 como fonte de resistência, embora tenham registrado $38,1 \%$ de plantas mortas em um dos ensaios. Posteriormente, Norton e Cosper (1985) confirmaram a resistência de PI 189225 e comentaram que este genótipo, além do PI 271778, possibilitaram retrocruzamentos que resultaram no lançamento de genótipos resistentes ao patógeno e à antracnose. No Brasil, em um dos ensaios de Dias et al. (1996), o acesso PI 189225 apresentou apenas $16,6 \%$ e $41,7 \%$ de plantas respectivamente resistentes e medianamente resistentes. Mesmo assim, PI 189225 diferiu significativamente de 'Crimson Sweet', que foi classificada como altamente suscetível, mesma classificação encontrada neste trabalho. Desta forma, observa-se falta de estabilidade na resistência de PI 189225 a D. bryoniae indicando que o material estaria segregando para esta característica.

Nos ensaios desenvolvidos em casa de vegetação, com relação à infecção média de três isolados de $D$. bryoniae no caule, apenas a cv. Riviera diferiu estatisticamente de 'Crimson Sweet' (Tabela 2). As cvs. Eureka, Rubi e Savana não se separaram de Riviera. Esses resultados foram semelhantes aos encontrados em campo, com exceção da cv. Rubi, que no ensaio de campo demonstrou alto grau da doença nas folhas (Tabela 2). Todos os isolados foram patogênicos a todas cultivares e não houve interação significativa entre cultivares $\mathrm{x}$ isolados, demonstrando dessa forma a falta de especificidade entre os

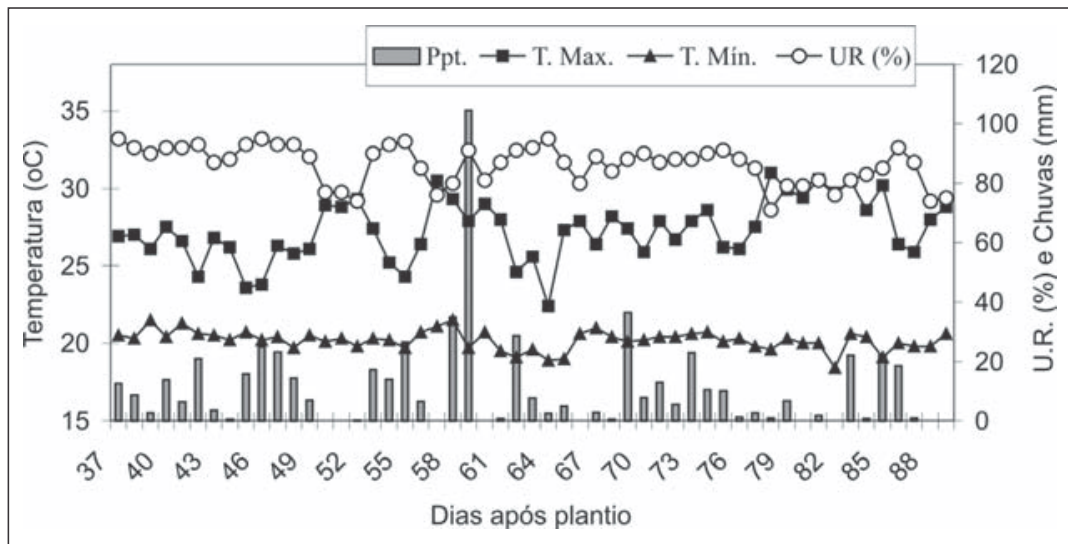

Figura 3.Temperaturas máxima e mínima $\left({ }^{\circ} \mathrm{C}\right)$, umidade relativa do ar $(\%)$ e chuvas $(\mathrm{mm})$ a partir de 37 dias após o plantio. Brasília, UnB, 2003/2004.

isolados testados. Falta de especificidade entre isolados de $D$. bryoniae foi relatada por Keinath et al. (1995), quando compararam isolados do patógeno de cucurbitáceas obtidos na Carolina do Sul, Flórida e Nova York, e verificaram que dos 19 isolados testados 17 foram patogênicos à melancia e ao melão Cantaloupe (Cucumis melo). De modo geral esses autores relataram pouca diversidade quanto à virulência.

Foi encontrada correlação significativa $(r=0,77)$ entre as AACPDs do ensaio de campo (resistência das folhas) e de casa de vegetação (resistência no caule), sugerindo que a metodologia utilizada em condição controlada pode ter valor auxiliar na avaliação de grande número de plantas em programas de melhoramento. Entretanto, a seleção final de cultivares resistentes deve ser feita a campo. Os resultados deste trabalho poderão ser aplicados imediatamente para o manejo integrado do crestamento gomoso do caule da melancia.

\section{AGRADECIMENTOS}

O primeiro autor foi bolsista de doutorado e o segundo é bolsista de pesquisa do CNPq. O trabalho também recebeu apoio financeiro adicional através do Processo CNPq no. 474194/2003-5.

\section{LITERATURA CITADA}

ARNY, C.J.; ROWE, R.C. Effects of temperature and duration of surface wetness on spore production and infection of cucumbers by Didymella bryoniae. Phytopathology. v.81, p.206209, 1991.
BALA, G.; HOSEIN, F. Studies on gummy stem blight disease of cucurbits in Trinidad. Tropical Agriculture (Trinidad) v.63, p.195-197, 1986.

BLANCARD, D.; LECOQ, H.; PITRAT, M. Enfermedades de las cucurbitáceas. INRA, John Wiley \& Sons, 301 p, 1996, p.210-211.

CAFÉ FILHO, A.C.; SANTOS, G.R. Ocorrência do crestamento gomoso do caule em melancia no Estado do Tocantins, descrição e ilustração do agente causal, Didymella bryoniae. Fitopatologia Brasileira, v.29 (Suplemento), p.57, 2004. (Resumo) CHIU, W.F.; WALKER, J.C. Physiology and pathogenicity of the cucurbit black-rot fungus. Journal of Agricultural Research, v.78, p.589615, 1949.

COHEN, R. Variability in the reaction of squash (Cucurbita pepo) to inoculation with Sphaerotheca fuliginea and methodology of breeding for resistance. Plant Pathology, v.42, n.4, p.510-516, 1993.

DIAS, R.C.S.; QUEIROZ, M.A.; MENEZES, M. Identificação de fontes de resistência em melancia a Didymella bryoniae. Horticultura Brasileira, Brasília, v.14, n.1, p.15-17, 1996.

DUSI, A.N.; TASAKI, S.; VIEIRA, J.V. Metodologia para avaliação de resistência a Didymella bryoniae em melão. Horticultura Brasileira, Brasília, v.12, n.1, p.43-44, 1994.

EVERTS, K.L. First report of benomyl resistance of Didymella bryoniae in Delaware and Maryland. Plant Disease, v.83, p.304, 1999.

FIGUEIREDO, M.B.; CARDOSO, R.M.G.; ABRAHÃO, J. Perdas causadas pelo fungo Mycosphaerella melonis (Pass.) Chiu \& J.C. Walker em aboboreira de moita. O Biológico, São Paulo, v.32, p.203-205, 1964.

KEINATH, A.P. Fungicide timing for optimum management of gummy stem blight epidemics on watermelon. Plant Disease, v.79, n.4, p.354-358, 1995. KEINATH, A.P. FARNHAM, M.W.; ZITTER, T.A. Morphological, pathological, and genetic differentiation of Didymella bryoniae and Phoma spp. isolated from cucurbits. Phytopathology, v.85, p.364-69, 1995.

KEINATH, A.P.; DUTHIE, I.A. Yield and quality reductions in watermelon due to anthracnose, gummy stem blight and black rot. p.77-90. in: Recent Research Developments in Plant Pathology, vol.2, Research Signpost, Trivandrum, India, 1998. 
MALATHRAKIS, N.E.; VAKALOUNAKIS, D.J. Resistance to benzimidazole fungicides in the gummy stem blight pathogen Didymella bryoniae on cucurbits. Plant Pathology, v.32, p.395-399, 1983. MCGRATH, D.J.; VAWDREY, L.; WALKER, I.O. Resistance to gummy stem blight in muskmelon. HortScience. v.28, p.930-931, 1993. NORTON, J.D.; COSPER, R.D. Breeding watermelons for disease resistance. Phytopathology, v.75, n.10, p.1178, 1985.

PUNITHALINGAM, E.; HOLLIDAY, P Didymella bryoniae. CMI Descriptions of Pathogenic Fungi and Bacteria, n.332, 1972.

SANTOS, G.R.; CAFÉ-FILHO, A.C.; REIS, A. Resistência de Didymella bryoniae a benzimidazóis no Brasil. Fitopatologia Brasileira. Brasilia. v.29 (Suplemento), p.60-61, 2004.

SANTOS, G.R.; CAFÉ-FILHO, A.C.; SABOYA, L.M.F. Controle químico do crestamento gomoso do caule em melancia. Fitopatologia Brasileira. Brasília. v.30, n.2, p.155-163, 2005a.
SANTOS, G.R.; CAFÉ-FILHO, A.C.; LEÃO, F.F.; CÉSAR, M.; FERNANDES, L.E. Progresso do crestamento gomoso e perdas na cultura da melancia. Horticultura Brasileira, Brasília, v.23, n.2, p.230-234, 2005b.

SCHENCK, N.C. Watermelon disease incidence in central Florida. Plant Disease Reporter, v.44, p.556-568, 1960 .

SCHENCK, N.C. Epidemiology of gummy stem blight (Mycosphaerella citrulina) on watermelon: ascospore incidence and disease development. Phytopathology, v.58, p.1420-1422, 1968.

SITTERLY, W.R.; KEINATH, A.P. Gummy stem blight. p.27-28. in: Compendium of Cucurbit Diseases, T.A. Zitter, D.L. Hopkins \& C.E. Thomas, eds. APS Press, St Paul., 1996.

SHANER, G.; FINNEY, R.E. The effect of nitrogen fertilization on the expression of slowmildewing resistance in Knox wheat. Phytopathology, v.67, p.1051-1056, 1977.
SOWELL, G.Jr.; POINTER, G.R. Gummy stem blight resistance of introduced watermelons. Plant Disease Report, v.46, n.12, p.883-885, 1962.

SUMNER, D.R.; HALL, M.R. Resistance of watermelon cultivars to Fusarium wilt and gummy stem blight. Biological and Cultural Tests. v.8, p.36, 1993.

SVEDELIUS, G.; UNESTAM, T. Experimental factors favouring infection of attached cucumber leaves by Didymella bryoniae. Transactions of British Mycological Society, v.71, p.89-97, 1978. VAN STEEKELENBURG, N.A.M. Influence of humidity on incidence of Didymella bryoniae on cucumber leaves and growing points under controlled environmental conditions. Netherland Journal of Plant Pathology, v.91, p.253-264, 1985. WEHNER, T.C.; St. AMAND, P.C. Field tests for cucumber resistance to gummy stem blight in North Carolina. HortScience. v.28, p.327-329, 1993. 